\title{
Cerebral fat embolism syndrome following revision of right total hip arthroplasty
}

\author{
Ruben Carmona, August Tuan, Tudor H Hughes, Stephen M Dorros
}

Department of Radiology, University of California San Diego, San Diego, California, USA

\section{Correspondence to}

Professor Stephen M Dorros, sdorros@ucsd.edu

Accepted 16 April 2014

\section{DESCRIPTION}

A 74-year-old man underwent an uncomplicated right total hip arthroplasty revision. Postoperatively, the patient had no focal neurological deficits. Twelve hours later, his mental status declined and he was subsequently intubated. He had roving eyes, decerebrate posturing and minor grimacing to noxious stimuli. He never developed a petechial rash. EEG was unremarkable for seizure activity, transoesophageal echocardiography was negative for cardioembolic sources or interatrial septal defects, and neck CT angiography demonstrated no vascular abnormalities. Head CT was unremarkable and diffusion-weighted images (DWI) of the brain showed multiple foci of restricted diffusion, compatible with acute/subacute infarcts (figure 1A-C). The initial $\mathrm{T} 2$ *-weighted gradient echo MRI (GRE) was normal (figure 1D); however, 3 days later the same sequence showed areas of susceptibility, compatible with diffuse microhaemorrhages (figure 1E). The patient's clinical course and imaging findings were consistent with cerebral fat embolism (CFE) and the diagnosis was made. CFE occurs in $0.5-3.5 \%$ of long bone fractures. Fortunately, some patients recover completely with supportive care. ${ }^{1}$ Hyperintensities on DWI reflect areas of cytotoxic oedema from microinfarcts. DWI findings have been reported in patients following emergency surgery due to hip fracture ${ }^{2}$ and in the absence of intracardiac shunts, ${ }^{3}$ but rarely after

\section{Learning points}

- Cerebral fat embolism is demonstrated by the classic 'starfield' pattern on diffusion-weighted imaging. The differential diagnosis includes acute embolic infarction, vasculitis and posterior reversible encephalopathy syndrome.

- $\mathrm{T}^{*}$-weighted gradient echo MRI is also a sensitive method to detect cerebral fat emboli, which are demonstrated by areas of susceptibility that are compatible with microhaemorrhages.

- Cerebral fat embolism syndrome, while known to occur in patients with acute traumatic long bone fractures, may also occur following elective orthopaedic surgeries.
To cite: Carmona $\mathrm{R}$ Tuan A, Hughes TH, et al. BMJ Case Rep Published online: [please include Day Month Year] doi:10.1136/ bcr-2014-204955

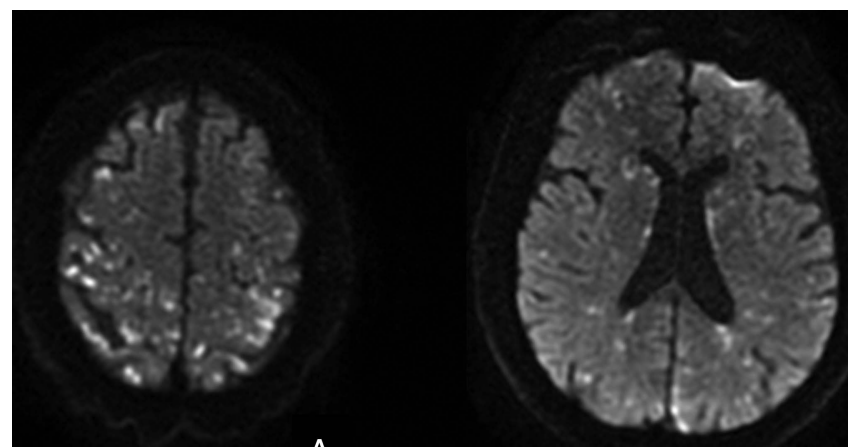

A

B

C

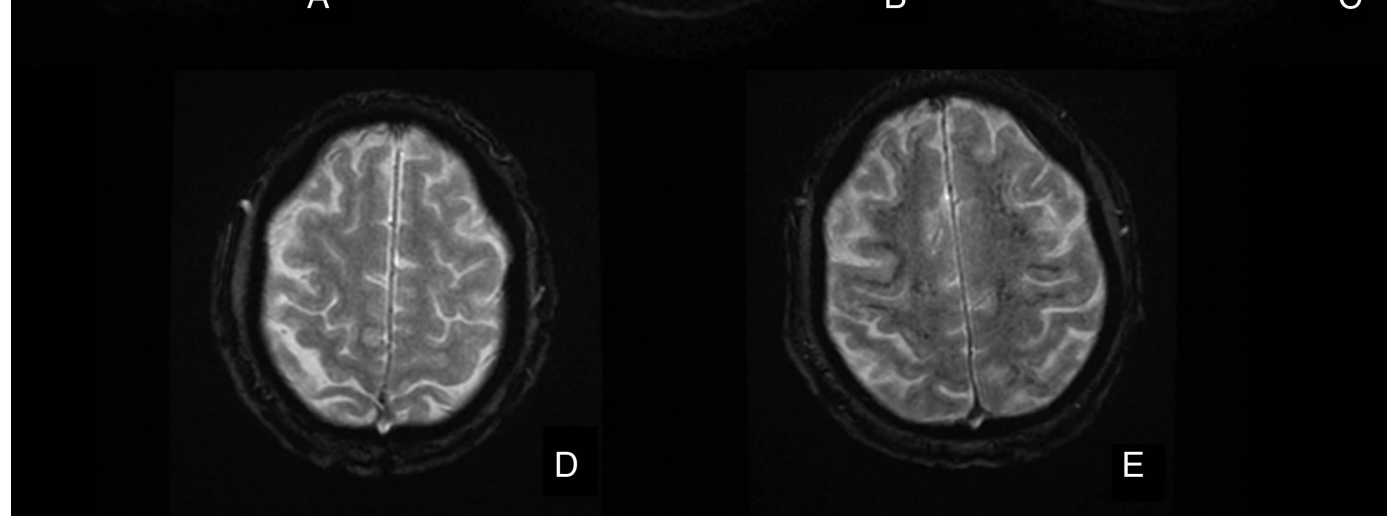

Figure 1 MRI of the cerebral fat embolism. Diffusion-weighted MRI performed on postoperative day (POD) 1 show multiple bilateral and symmetric foci of restricted diffusion throughout the cerebrum and cerebellum, compatible with acute/subacute infarcts (A-C). T2*-weighted gradient echo MRI on POD1 is normal (D). A repeat T2*-weighted gradient echo MRI performed on POD3 shows a new foci of susceptibility in the bilateral subcortical white matter, compatible with diffuse microhaemorrhages (E). 
elective hip revision. GRE findings have only been identified several weeks after surgery. ${ }^{1}$ We present images in the acute postoperative period. There are two theories regarding the aetiology of CFE: one involves an embolic passage via pulmonary capillaries, and the other hypothesises inflammatory processes due to free fatty acid formation.

Contributors RC and AT collected the clinical history, acquired the images and prepared the manuscript. THH and SMD conceptualised the work, interpreted the images and finalised the manuscript.

Competing interests None.
Patient consent Obtained.

Provenance and peer review Not commissioned; externally peer reviewed.

\section{REFERENCES}

1 Lee J. Gradient-echo MRI in defining the severity of cerebral fat embolism. J Clin Neurol 2008:4:164-6.

2 Goenka N, Ropper AH. Images in clinical medicine. Cerebral fat embolism. N Engl J Med 2012;367:1045.

3 Ammon JT, Khalily C, Lester DK. Fatal cerebral emboli in the absence of a cardiac arterial-venous shunt: case report. J Arthroplasty 2007;22:477-9.

Copyright 2014 BMJ Publishing Group. All rights reserved. For permission to reuse any of this content visit http://group.bmj.com/group/rights-licensing/permissions.

BMJ Case Report Fellows may re-use this article for personal use and teaching without any further permission.

Become a Fellow of BMJ Case Reports today and you can:

- Submit as many cases as you like

- Enjoy fast sympathetic peer review and rapid publication of accepted articles

- Access all the published articles

- Re-use any of the published material for personal use and teaching without further permission

For information on Institutional Fellowships contact consortiasales@bmjgroup.com

Visit casereports.bmj.com for more articles like this and to become a Fellow 